\title{
Outcomes of Patients with Central Precocious Puberty Due to Loss-of-Function Mutations in the MKRN3 Gene after Treatment with Gonadotropin-Releasing Hormone Analog
}

\author{
Carolina de Oliveira Ramos $^{a}$ Delanie B. Macedo ${ }^{a}$ Ana Pinheiro M. Canton ${ }^{a}$ \\ Marina Cunha-Silva ${ }^{a}$ Sonir R.R. Antonini ${ }^{b}$ Monica Freire Stecchini ${ }^{b}$ \\ Carlos Eduardo Seraphim $^{a}$ Tania Rodrigues ${ }^{c}$ Berenice Bilharinho Mendonca ${ }^{a}$ \\ Ana Claudia Latronico ${ }^{a}$ Vinicius Nahime Brito ${ }^{a}$

\begin{abstract}
a Unidade de Endocrinologia do Desenvolvimento, Disciplina de Endocrinologia e Metabologia da Faculdade de Medicina da Universidade de São Paulo e Laboratório de Hormônios e Genética Molecular LIM 42 do Hospital das Clínicas, São Paulo, Brazil; ${ }^{b}$ Departamento de Pediatria, Escola de Medicina de Ribeirão Preto, Universidade de São Paulo, Ribeirão Preto, Brazil; ' Departamento de Medicina, Universidade Federal de Juiz de Fora- Campus Governador Valadares, Governador Valadares, Brazil
\end{abstract}

\author{
Keywords \\ Central precocious puberty · Gonadotropin-releasing \\ hormone analog $\cdot$ MKRN3 · Final height · Body \\ composition · Gonadal function
}

\begin{abstract}
Introduction: Loss-of-function mutation of MKRN3 represents the most frequent genetic cause of familial central precocious puberty (CPP). The outcomes of gonadotropin-releasing hormone analog ( $\mathrm{GnRHa}$ ) treatment in CPP patients with MKRN3 defects are unknown. Objective: To describe the clinical and hormonal features of patients with CPP with or without MKRN3 mutations after GnRHa treatment. Anthropometric, metabolic and reproductive parameters were evaluated. Patients and Methods: Twenty-nine female patients with CPP due to loss-of-function mutations in the MKRN3 and 43 female patients with idiopathic CPP were included. Their medical records were retrospectively evaluated for clinical, laboratory, and imaging study, before, during,
\end{abstract}

karger@karger.com

(c) 2019 S. Karger AG, Basel

www.karger.com/nen

Karger and after GnRHa treatment. All patients with idiopathic CPP and 11 patients with CPP due to MKRN3 defects reached final height (FH). Results: At the diagnosis, there were no significant differences between clinical and laboratory features of patients with CPP with or without MKRN3 mutations. A high prevalence of overweight and obesity was observed in patients with CPP with or without MKRN3 mutations (47.3 and $50 \%$, respectively), followed by a significant reduction after $\mathrm{GnRHa}$ treatment. No significant differences in the values of mean $\mathrm{FH}$ and target height were found between the 2 CPP groups after GnRHa treatment. Menarche occurred at the expected age in patients with or without CPP due to MKRN3 mutations (11.5 \pm 1.3 and $12 \pm 0.6$ years, respectively). The prevalence of polycystic ovarian syndrome was $9.1 \%$ in patients with CPP due to MKRN3 mutations and 5.9\% in those with idiopathic CPP. Conclusion: Anthropometric, metabolic, and reproductive outcomes after GnRHa treatment were comparable in CPP patients, with or without MKRN3 mutations, suggesting the absence of deleterious effects of MKRN3 defects in young female adults' life.

(C) 2019 S. Karger AG, Base

Vinicius Nahime Brito, $\mathrm{MD}, \mathrm{PhD}$

Av Dr Enéas de Carvalho Aguiar, 2552 andar Bloco 6

Cerqueira Cesar, São Paulo, SP CEP 05403900 (Brazil)

E-Mail vinicius.brito@hc.fm.usp.br; carolinaramos50@ hotmail.com 


\section{Introduction}

Central precocious puberty (CPP) refers to the onset of pubertal signs before the age of 8 in girls and 9 in boys because of the early activation of the hypothalamic-pituitary-gonadal axis $[1,2]$. The absence of organic abnormalities of the central nervous system or genetic causes classifies CPP as "idiopathic." In contrast, several cerebral malformations and acquired insults can cause "organic" CPP [3]. CPP can also be classified as sporadic or familial forms $[2,3]$.

In the last decade, the genetic causes of CPP were identified in previously considered idiopathic CPP. Abreu et al. [4] identified loss-of-function mutations in MKRN3 (makorin ring-finger 3 gene), in $33 \%$ of the families who had members with CPP. MKRN3 is a maternally imprinted gene, located at chromosome 15q11.2 in the PraderWilli syndrome critical region, and it encodes the makorin ring-finger protein 3 with a potential inhibitory effect on gonadotropin-releasing hormone $(\mathrm{GnRH})$ secretion [4]. The reduction in MKRN3 expression in arcuate nucleus at the onset of puberty in mice, together with the identification of loss-of-function mutations in humans with familial CPP, implies that MKRN3 might control puberty by repressing downstream targets instead of activating the GnRH neuronal network $[4,5]$. To date, loss-offunction mutations in MKRN3 represent the most frequent genetic cause of familial CPP [6, 7]. In addition, a rare deletion in the regulatory region of $M K R N 3$ was also described in 1 patient with apparently sporadic CPP [8].

Since the 1980, long-acting GnRH analog (GnRHa) has been the first-line treatment for CPP of all etiologies $[9,10]$. Several studies on long-term outcomes after discontinuation of GnRHa treatment in patients with idiopathic CPP have been reported $[9,11-15]$. It has been demonstrated that GnRHa treatment preserved the genetic adult height potential in patients with idiopathic CPP especially if diagnosed before the age of 6 years [10]. Overweightness and obesity are common at the diagnosis of CPP, and GnRHa treatment has no impact on the body mass index (BMI). However, an increase of body fat mass percentage has been demonstrated during GnRHa treatment $[16,17]$. It has been demonstrated that gonadal function is completely recovered in patients after discontinuation of GnRHa treatment, and reports on the prevalence of polycystic ovarian syndrome (PCOS), in both treated and untreated women, still remain controversial $[15,17]$. However, there is no report on the long-term follow-up of patients with CPP due to MKRN3 mutations after GnRHa treatment.
In this study, we described the initial clinical and laboratory features of $29 \mathrm{CPP}$ patients with CPP due to lossof-function mutations of $M K R N 3$, as well the long-term follow-up features after GnRHa treatment of a subset of 11 female patients, emphasizing on anthropometric, metabolic, and reproductive outcomes during early adulthood. Furthermore, their data were compared with those from 43 patients with idiopathic CPP treated with GnRHa.

\section{Patients and Methods}

This is an observational, retrospective, and longitudinal study of a multicenter cohort of 72 female patients with CPP (29 patients with CPP due to MKRN3 mutations and 43 with idiopathic CPP). Fifty-one female patients were diagnosed and treated at the Developmental Endocrinology Unit of the Endocrinology and Metabolism Division of the Sao Paulo University Medical School, between 1985 and 2019. The remaining 21 female patients with CPP due to MKRN3 mutations were referred from other national (Ribeirao Preto Medical School, University of Sao Paulo; Universidade Estadual de Campinas, Faculdade de Ciências Médicas; private office Governador Valadares-MG; Universidade do Estado do Rio de Janeiro-RJ) and international Services (Division of Endocrinology, Diabetes, and Metabolism, Nemours Children's Clinic, Jacksonville, FL, USA; Department of Pediatrics, University Hospital Gasthuisberg, University of Leuven, Leuven, Belgium; Hospital de Niños R. Gutiérrez, Buenos Aires, Argentina; Department of Pediatric Endocrinology, University of Health Sciences, Umraniye Training and Research Hospital, Adem Yavuz Caddesi, Elmalıkent Mah. Yekta Sok., Istanbul, Turkey; Pediatric Endocrine and Diabetes Unit the Chaim Sheba Medical Center, Israel) for genetic study at the Laboratory of Hormones and Molecular Genetics LIM/42 of the Medical School of the University of São Paulo and they followed their directions.

The diagnosis of CPP was based on pubertal development before the age of 8 years, accelerated growth velocity, advanced bone maturation, and pubertal basal and/or GnRH-stimulated LH levels [1]. All patients were treated exclusively with GnRHa, with monthly (3.75 mg leuprorelin) and/or quarterly dosage ( $11.25 \mathrm{mg}$ leuprorelin). Height was considered final if the growth rate was $>0.5 \mathrm{~cm} /$ year during the preceding year and bone age (BA) was $>15$ years [13].

Serum LH (luteinizing hormone), FSH (follicle stimulating hormone), total testosterone, and estradiol levels were measured by radioimmunoassay till 1991, immunofluorometric assay (IFMA, AutoDELFIA, Turku, Finland) till 2012, and electroimmunochemiluminescence assays (ECLIA, cobas e601, Roche Diagnostics, Indianapolis, IN, USA) after 2012. Basal LH >0.6 IU/L (IFMA) or $>0.3$ IU/L (ECLIA) were considered as pubertal levels $[18,19]$. Progesterone, DHEA-S (dehydroepiandrosterone sulfate), and insulin levels were assessed by ECLIA. Androstenedione was assessed by liquid chromatography and mass spectrometry. All assays presented intra- and inter-assay coefficients of variation $<7 \%$. Pubertal response was considered when GnRH/GnRHastimulated LH peak was $>15$ IU/L for girls and $>25.5$ IU/L for boys (radioimmunoassay), $>6.9$ IU/L for girls and $>9.6$ IU/L for boys 
(IFMA), and $>8$ IU/L for both sexes (ECLIA) $[18,19]$. BA was assessed using the Greulich and Pyle's method [20].

All patients underwent brain magnetic resonance imaging study, which included pre- and post-gadolinium-enhanced sagittal T1-weighted images, as well as coronal T1- and T2-weighted images, with 3-mm slices [21].

The GnRHa depot (3.75 or $11.25 \mathrm{mg}$ leuprorelin acetate) was administered subcutaneously or intramuscularly, every 28 or 84 days respectively. The clinical and laboratory parameters were monitored every 3 months to assess the regression or stabilization of secondary sexual characters, adequate growth velocity, and suppressed sexual steroids levels with basal and/or GnRH-stimulated LH levels at prepubertal range (basal $\mathrm{LH}<0.6$ IU/L for IFMA and $<0.2$ IU/L for ECLIA; LH: 120 min after GnRHa <4 IU/L) [22]. BA was assessed yearly once. GnRHa treatment was discontinued when normal puberty could be expected (10-14 years) and, ideally, when normal height for chronological age (CA) and BA was reached. Target height $(\mathrm{TH})$ was calculated from parents' height measurements and determined as follows: mid-parental height minus $6.5 \mathrm{~cm}$ for girls or plus $6.5 \mathrm{~cm}$ for boys. TH range was established as $\mathrm{TH} \pm 8.5 \mathrm{~cm}[23,24]$.

The BMI (weight $[\mathrm{kg}] /$ square of height $[\mathrm{m}]$ ) was calculated using documented anthropometric measurements. Among children and adolescents ( $<18$ years), BMI percentiles were used to define overweightness ( $\geq 85$ th) and obesity ( $\geq 95$ th) [25]. For BMI calculation in adults, the index of body weight, according to the WHO criteria, was applied: underweight $<18.5 \mathrm{~kg} / \mathrm{m}^{2}$, normal weight $18.5-24.9 \mathrm{~kg} / \mathrm{m}^{2}$, overweight $25.0-29.9 \mathrm{~kg} / \mathrm{m}^{2}$, and obesity $>30 \mathrm{~g} /$ $\mathrm{m}^{2}[26]$.

The assessment of body composition was done using multifrequency bioimpedance analysis (In-Body 720, Biospace, Seoul, Korea); in this method, the body composition is analyzed by plethysmography multifrequency, in which body readings are made using 8 electrodes measuring the resistance in 5 specific frequencies and reactance in 3 specific frequencies.

Metabolic parameters were assessed by measuring fast glucose, insulin, HOMA-IR, total cholesterol and fractions (HDL and LDL), and triglycerides levels. Insulin resistance was considered to prevail at the value of HOMA-IR > 3.80 [27]. Blood pressure was assessed in all patients and hypertension was defined with values of systolic blood pressure $\geq 140 \mathrm{~mm} \mathrm{Hg}$ and diastolic blood pressure $\geq 90 \mathrm{~mm} \mathrm{Hg}$ [25].

After the discontinuation of GnRHa treatment, resumption of menarche, menstrual cycle pattern, achievement of pregnancy, and birth of live fetus were documented in females. The reproductive function in females during adulthood was evaluated by the measurement of gonadotropins and estradiol at the follicular phase as well as uterine length, ovarian morphology through pelvic ultrasound at the follicular phase, and progesterone levels at the luteal phase. The polycystic ovarian morphology was defined by the presence of 12 or more follicles of $2-9 \mathrm{~mm}$ in diameter and/or an increased ovarian volume $>10 \mathrm{~mL}$ (without a cyst or dominant follicle) in either ovary [28].

Signs of clinical hyperandrogenism, including acne (severity and localization) and presence and degree of hirsutism (scored by Ferriman-Gallwey scale), were also evaluated. Laboratory hyperandrogenemia was assessed by measuring DHEA-S, total testosterone, and androstenedione serum levels at the follicular phase. The diagnosis of PCOS was done according to Rotterdam's criteria [29].

Outcomes of Patients with CPP with or without MKRN3 Mutations

\section{Genetic Analysis}

Genomic DNA was isolated from peripheral blood leukocytes of all patients and selected family members using standard procedures (salting-out method). The entire coding region (intronless gene) and the promoter region of $M K R N 3$ were amplified by polymerase chain reaction followed by automatic sequencing of the products using the Sanger method in all patients, according to previously published protocol $[4,8]$.

\section{Statistical Analysis}

Statistical analysis was performed using SigmaStat for Windows version 3.5, Systat Software, Inc. Data are presented as mean \pm SDs or median and range. Comparisons among values of means of numerical variables were made using Student $t$ test or MannWhitney U test, when appropriate. Categorical variables were compared using chi-square test. For statistical purposes, the percentages of overweight and obesity (categorical variables) in each group were grouped. Correlations between 2 variables were determined by Pearson's correlation coefficient analysis. Statistical significance was set at $p<0.05$.

\section{Results}

\section{Clinical and Hormonal Data at the Onset of Puberty}

The mean CA of onset of puberty was $5.9 \pm 1.2$ years and $6.4 \pm 1.3$ years in patients with CPP due to MKRN3 mutations and idiopathic CPP groups respectively $(p=$ 0.12 ). In addition, the mean BA at the onset of puberty was $9 \pm 1.6$ years and $10.5 \pm 1.3$ years in patients with CPP due to $M K R N 3$ mutation and idiopathic CPP groups respectively $(p<0.001)$. Familial history of precocious puberty was positive in all patients with CPP due to MKRN3 mutations and $25.6 \%$ of those with idiopathic CPP. The mean height SDS at the diagnosis was $1.4 \pm 0.9$ in patients with CPP due to $M K R N 3$ mutation and $1.7 \pm 1.1$ in patients with idiopathic CPP $(p=0.34)$. At the onset of puberty, the prevalence of overweightness and obesity was observed in $47.3 \%$ of girls with CPP due to MKRN3 mutations and $50 \%$ of those with idiopathic CPP.

At the diagnosis, mean basal LH was at pubertal levels in $96 \%$ of patients with CPP due to MKRN3 mutations and in $73.1 \%$ of patients with idiopathic CPP ( $1.4 \pm 0.9 \mathrm{vs}$. $1.7 \pm 1.7 \mathrm{IU}, p=0.35)$. The mean GnRH-stimulated LH peak was at the pubertal range in all patients from both groups, $24.9 \pm 19.8$ vs. $18.7 \pm 11.2$ IU in patients with CPP due to $M K R N 3$ mutations and idiopathic CPP groups, respectively, $p=0.8$. Mean basal FSH and estradiol levels before GnRHa treatment did not differ between groups, $p=0.8$ and 0.17 , respectively. Clinical and hormonal data at the diagnosis are summarized in the Table 1.

In the 29 patients with CPP due to $M K R N 3$ mutations, 13 distinct inactivating mutations in the coding region of 
Table 1. Initial clinical and hormonal features of female patients with CPP due to MKRN3 loss-of-function mutations and idiopathic form

\begin{tabular}{|c|c|c|c|}
\hline & $\begin{array}{l}\text { CPP due to MKRN3 } \\
\text { mutation }\end{array}$ & $\begin{array}{l}\text { Idiopathic } \\
\text { CPP }\end{array}$ & $p$ value \\
\hline Number & 29 & 43 & \\
\hline CA at pubertal onset, years, mean $\pm \mathrm{SD}$ & $5.9 \pm 1.2$ & $6.4 \pm 1.3$ & 0.12 \\
\hline $\mathrm{CA}$ at first visit, years, mean $\pm \mathrm{SD}$ & $6.8 \pm 0.9$ & $8.1 \pm 1.3$ & $<0.001$ \\
\hline \multicolumn{4}{|l|}{ Pubertal stage } \\
\hline Breast development & B2-B5 & $\mathrm{B} 2-\mathrm{B} 4$ & \\
\hline Pubic hair & $\mathrm{PH} 1-\mathrm{PH} 3$ & PH1-PH3 & - \\
\hline Menarche & None & $3 / 43$ & \\
\hline Familial CPP history, \% & 100 & $11 / 43(25.6)$ & NA \\
\hline Initial BA, years, mean \pm SD & $9 \pm 1.6$ & $10.5 \pm 1.3$ & $<0.001$ \\
\hline$\Delta \mathrm{BA}-\mathrm{CA}$, years, mean $\pm \mathrm{SD}$ & $2.1 \pm 1.4$ & $2.3 \pm 1.2$ & 0.7 \\
\hline Height, $\mathrm{cm}$, mean $\pm \mathrm{SD}$ & $127.8 \pm 8.2$ & $135.6 \pm 8.1$ & 0.02 \\
\hline Height, mean \pm SD & $1.4 \pm 0.9$ & $1.7 \pm 1.1$ & 0.34 \\
\hline BMI, $\mathrm{kg} / \mathrm{m}^{2 *}$ & $16.8(15.6-19.3)$ & $17.9(12.2-22.6)$ & 0.14 \\
\hline Overweight/obesity, \% & $47.3(26.3 / 21)$ & $50(26.2 / 23.8)$ & 0.16 \\
\hline Basal LH, IU/L, mean \pm SD & $1.4 \pm 0.9$ & $1.7 \pm 1.7$ & 0.35 \\
\hline $\mathrm{LH}$ peak, IU/L, mean $\pm \mathrm{SD}$ & $24.9 \pm 19.8$ & $18.7 \pm 11.2$ & 0.18 \\
\hline Basal FSH, IU/L, mean \pm SD & $4.6 \pm 1.9$ & $4.4 \pm 2.8$ & 0.8 \\
\hline Basal estradiol, $\mathrm{ng} / \mathrm{mL}$, mean $\pm \mathrm{SD}$ & $35.4 \pm 22.1$ & $27.8 \pm 19.4$ & 0.17 \\
\hline
\end{tabular}

$M K R N 3$, and 1 deletion in the promoter region were identified. Twenty-two patients (75.8\%) had severe mutations (18 frameshifts, 3 nonsense mutations, and 1 deletion) and 7 patients had missense mutations.

During GnRHa treatment, all patients with CPP patients, with or without MKRN3 mutation, reached adequate clinical and hormonal controls, according to clinical and laboratory criteria mentioned earlier in this manuscript (data not shown).

\section{Anthropometric Data after GnRHa Treatment and at the Final Height}

Final height $(\mathrm{FH})$ was achieved in 11 patients with $\mathrm{CPP}$ due to MKRN3 mutations and in all patients with idiopathic CPP. In these patients, the mean duration of GnRHa treatment was $2.9 \pm 0.9$ and $2.6 \pm 1.1$ years in patients with CPP due to MKRN3 mutation and idiopathic CPP, respectively, $(p=0.55)$. In the patients with CPP due to MKRN3 mutations, the mean CA and BA at the end of GnRHa treatment was $10.6 \pm 1$ and $12.5 \pm 0.9$ years, respectively. In the idiopathic CPP group, the mean CA and $\mathrm{BA}$ at the end of GnRHa treatment was $10.9 \pm 0.5$ and 12.3 \pm 0.7 years respectively. The mean height SDS at the end of treatment was $1.2 \pm 1.3$; and there was prevalence of overweight, or obesity was present in $36.2 \%$ of patients with CPP due to MKRN3 mutations group. In patients with idiopathic CPP, the mean height SDS at the end of treatment was $1.3 \pm 1.1$; and there was prevalence of overweight or obesity was present in $47.5 \%$ of the patients. There were no statistically significant differences in these variables between groups ( $p>0.05$; Table 2$)$. At the last visit, the mean CA of the patients with CPP due to MKRN3 mutations and idiopathic CPP was $18.6 \pm 4$ and $16.6 \pm 3.2$ years respectively $(p=0.14)$. The mean post-treatment growth until reaching $\mathrm{FH}$ was $9.6 \pm 3.6$ and $10.1 \pm 3.5 \mathrm{~cm}$ in patients with CPP due to MKRN3 mutations and idiopathic CPP, respectively, $(p=0.6)$. The mean $\mathrm{FH}$ was $157.6 \pm 5.1$ and $161.3 \pm 6.5 \mathrm{~cm}$ in patients with CPP due to MKRN3 mutation and idiopathic CPP groups respectively $(p=0.09)$. All but 1 patient (patient $9-$ Table 3 ) with $\mathrm{CPP}$ due to MKRN3 mutation were within their TH range. The $\mathrm{FH}$ of $42 / 43$ patients was within their $\mathrm{TH}$ range in the idiopathic CPP group, and no statistically significant difference was found between mean FH and TH. With regard to the severity of MKRN3 mutations, 10 out of 11 patients harbored severe mutations ( 7 frameshifts, 2 nonsense mutations, and 1 deletion in the promoter region) and $1 \mathrm{pa}-$ tient had a missense MKRN3 mutation (Table 3). 
Table 2. Clinical and hormonal data of female patients with CPP due to MKRN3 loss-of-function mutations and idiopathic form at the end of GnRHa treatment, and at final height

\begin{tabular}{|c|c|c|c|}
\hline & $\begin{array}{l}\text { CPP due to } \\
M K R N 3 \text { mutations }\end{array}$ & Idiopathic CPP & $p$ value \\
\hline Number & 11 & 43 & \\
\hline \multicolumn{4}{|l|}{ At end of treatment, mean $\pm \mathrm{SD}$} \\
\hline CA, years & $10.6 \pm 1$ & $10.9 \pm 0.5$ & 0.1 \\
\hline $\mathrm{BA}$, years & $12.5 \pm 0.9$ & $12.3 \pm 0.7$ & 0.43 \\
\hline$\Delta \mathrm{BA}-\mathrm{CA}$, years & $2 \pm 1.2$ & $1.4 \pm 0.8$ & 0.1 \\
\hline Overweight/obesity, \% & 36.2 & 47.5 & 0.16 \\
\hline $\mathrm{BMI}, \mathrm{kg} / \mathrm{m}^{2 *}$ & $19.8(15.9-29.3)$ & $20.7(15.5-30)$ & 0.4 \\
\hline Height, cm & $148 \pm 5.4$ & $151.2 \pm 5.6$ & 0.12 \\
\hline Height & $1.2 \pm 1.3$ & $1.3 \pm 1.1$ & 0.68 \\
\hline Duration of treatment, years & $2.9 \pm 0.9$ & $2.6 \pm 1.1$ & 0.55 \\
\hline \multicolumn{4}{|l|}{ At final height, mean $\pm \mathrm{SD}$} \\
\hline CA, years & $18.6 \pm 4$ & $16.5 \pm 3.4$ & 0.14 \\
\hline Age at menarche, years & $11.5 \pm 1.3$ & $12 \pm 0.6$ & 0.1 \\
\hline \multicolumn{4}{|l|}{ Interval (age at menarche - end of GnRHa } \\
\hline treatment), years & $0.9 \pm 0.7$ & $1.1 \pm 0.5$ & 0.27 \\
\hline Post-treatment growth, $\mathrm{cm}$ & $9.6 \pm 3.7$ & $10.2 \pm 3.7$ & 0.6 \\
\hline Height, $\mathrm{cm}$ & $157.6 \pm 5.4$ & $161.4 \pm 6.6$ & 0.09 \\
\hline Height & $-0.7 \pm 0.9$ & $-0.15 \pm 1.1$ & 0.1 \\
\hline Target height, $\mathrm{cm}$ & $159.2 \pm 5.6$ & $159 \pm 6$ & 0.94 \\
\hline Target height & $-0.5 \pm 0.9$ & $-0.5 \pm 1$ & 0.94 \\
\hline $\mathrm{BMI}, \mathrm{kg} / \mathrm{m}^{2 *}$ & $21.4(17.4-36.8)$ & $22.7(17.4-31)$ & 0.6 \\
\hline Overweight/obesity, \% & 27.3 & 33.3 & 0.16 \\
\hline$\%$ fat mass, mean $\pm \mathrm{SD}, n$ & $35.4 \pm 16.7(3)$ & $31.6 \pm 6.7(28)$ & 0.43 \\
\hline \multicolumn{4}{|l|}{ Metabolic abnormalities } \\
\hline Insulin resistance, $n$ & $1 / 7$ & $4 / 35$ & 0.8 \\
\hline High LDL, $n$ & $2 / 7$ & $3 / 35$ & 0.2 \\
\hline Total metabolic dysfunction, $n(\%)$ & $3 / 7(42.8)$ & $6 / 35(17.1)$ & 0.25 \\
\hline Irregular menstrual cycles, $\%$ & 18.2 & 18.1 & 1.0 \\
\hline \multicolumn{4}{|l|}{ Hormonal data**, mean $\pm \mathrm{SD}, n$} \\
\hline LH, IU/L* & $4.5(0.8-19 ; 6)$ & $3.1(1.3-35.5 ; 34)$ & 0.5 \\
\hline FSH, IU/LS & $4.2 \pm 1.9(6)$ & $4.9 \pm 1.6(34)$ & 0.3 \\
\hline Estradiol, $\mathrm{pg} / \mathrm{mL}^{*}$ & $37.7(17-247 ; 6)$ & $59(14.6-391 ; 34)$ & 0.4 \\
\hline DHEA-S, ng/mL & $2,166 \pm 1,875(4)$ & $2,100 \pm 884(34)$ & 0.9 \\
\hline Androstenedione, $\mathrm{ng} / \mathrm{mL}$ & $1 \pm 0.4(3)$ & $1.4 \pm 0.7(34)$ & 0.4 \\
\hline Total testosterone, $\mathrm{ng} / \mathrm{dL}^{*}$ & $39.5(12-93 ; 4)$ & $31(12-79 ; 34)$ & 0.8 \\
\hline PCOS, $\%$ & 9.1 & 5.9 & 0.4 \\
\hline $\begin{array}{l}\text { * Median (interval). } \\
\text { ** Reference values: LH: } 2.4-12.8 \mathrm{IU} / \mathrm{L} ; \mathrm{FSH} \\
\text { ng/mL; androstenedione: } 0.25-2.2 \mathrm{ng} / \mathrm{mL} \text {; tot } \\
\text { CPP, central precocious puberty; GnRHa, } \\
\text { BA, bone age; BMI, body mass index; PCOS, }\end{array}$ & $\begin{array}{l}\mathrm{J} / \mathrm{L} ; \text { Estradiol: }<10-12 \\
\text { he: }<48 \mathrm{ng} / \mathrm{dL} . . \\
\text { in-releasing hormone } \\
\text { arian syndrome. }\end{array}$ & $\begin{array}{l}22 \mathrm{pg} / \mathrm{mL} ; \mathrm{DHEA}-\mathrm{S}: 1 \\
\text { analog; CA, chrono }\end{array}$ & $\begin{array}{l}480-4,070 \\
\text { ogical age; }\end{array}$ \\
\hline
\end{tabular}

The prevalence of overweight or obesity at the $\mathrm{FH}$ in patients with CPP due to MKRN3 mutation was $27.3 \%$ (3/11). In this group, only 3 patients underwent body composition analysis with a high mean percentage of body fat mass (35.4 $\pm 13.6 \%$ - reference value: $18-28 \%)$. In the idiopathic CPP group, the prevalence of over- weight and obesity at the $\mathrm{FH}$ was $34.8 \%(15 / 43)$ and the mean percentage of body fat mass was $31.6 \pm 6.6 \%$. The prevalence of categorical BMI percentiles and BMI revealed a significant decrease in the percentage of overweight and obesity from the diagnosis to $\mathrm{FH}$ in both groups $(p<0.05$; Fig. 1$)$. 
Table 3. Genetic and clinical data of 11 patients with CPP due to MKRN3 mutations after GnRHa treatment

\begin{tabular}{|c|c|c|c|c|c|c|c|c|}
\hline Patient & MKRN3 mutations & $\begin{array}{l}\text { CA at last } \\
\text { visit, years }\end{array}$ & $\begin{array}{l}\text { Post treatment } \\
\text { growth, } \mathrm{cm}\end{array}$ & $\mathrm{TH}, \mathrm{cm}$ & TH, SD & BMI & $\mathrm{FH}, \mathrm{cm}$ & $\mathrm{FH}, \mathrm{SD}$ \\
\hline 1 & p.Pro161Argfs*10 & 20.6 & 9.5 & 153 & -1.5 & 36.8 & 158.5 & -0.6 \\
\hline 2 & p.Gln226Thrfs*6 & 29.9 & 8 & 161.5 & -0.1 & 28.4 & 165 & 0.4 \\
\hline 3 & p.Glu256Glyfs*36 & 16.5 & 9 & 156.5 & -0.9 & 23.4 & 153 & -1.5 \\
\hline 4 & c. $-150 \_-147$ delTCAG & 16.3 & 9.9 & 163.5 & 0.2 & 21.4 & 162 & 0 \\
\hline 5 & p.Pro161Argfs*16 & 18.9 & 8.5 & 160.5 & -0.3 & 19.4 & 160.5 & -0.28 \\
\hline 6 & p.Pro161Arg fs*10 & 16 & 7.5 & 159.5 & -0.45 & 23.2 & 160.5 & -0.28 \\
\hline 7 & p.Phe417Ile & 14.6 & 13.5 & 156.2 & -1 & 17.9 & 162 & 0 \\
\hline 8 & p.Pro161Profs*16 & 15.7 & 1.5 & 152 & -1.7 & 31.3 & 149 & -2.2 \\
\hline 9 & p.Ala162Glyfs*15 & 18 & 11.5 & 170 & 1.3 & 18.1 & 159 & -0.53 \\
\hline 10 & p.Tyr391* & 20 & 10 & NA & NA & 20.1 & 148.5 & -2.2 \\
\hline 11 & p.Tyr391* & 18 & 16.5 & NA & NA & NA & 156 & -1 \\
\hline
\end{tabular}

$\mathrm{CPP}$, central precocious puberty; GnRHa, gonadotropin-releasing hormone analog; CA, chronological age; TH, target height; FH, final height; BMI, body mass index; NA, not available.

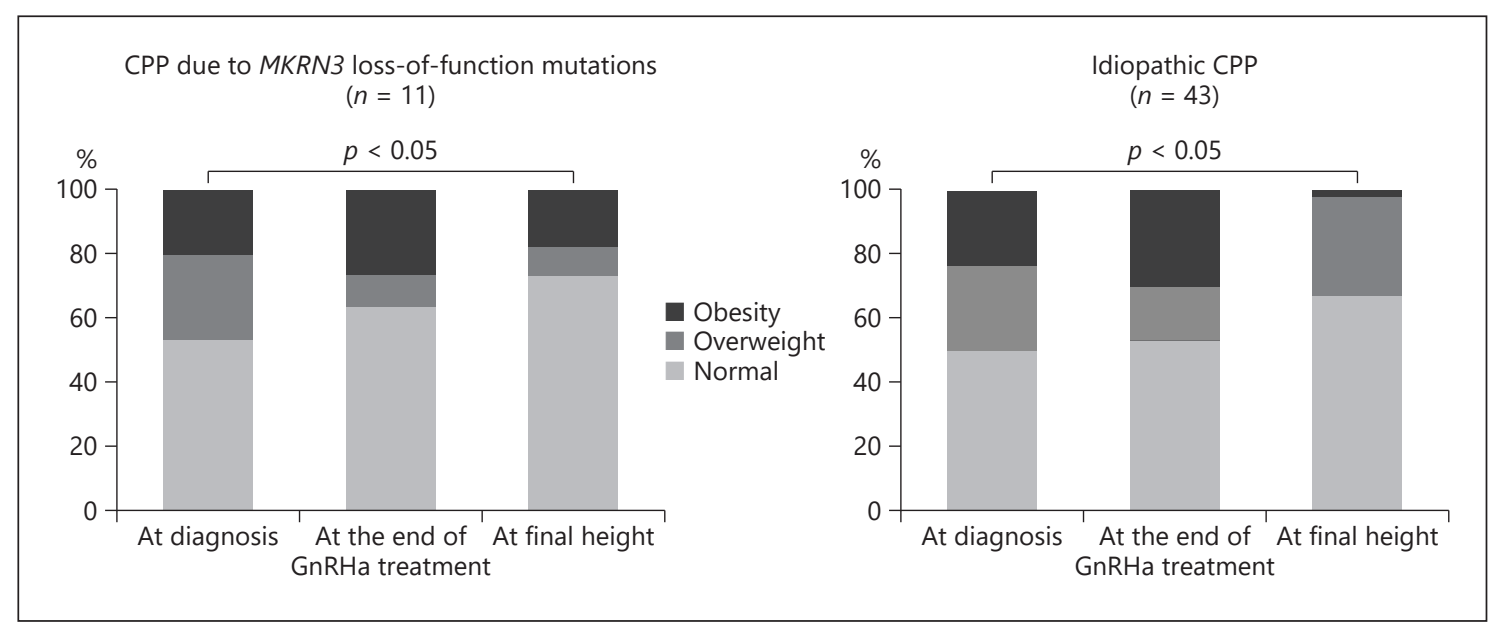

Fig. 1. Representation of the prevalence of categorical BMI at the diagnosis, at the end of GnRHa treatment, and at the $\mathrm{FH}$ in patients with CPP due to MKRN3 mutations and idiopathic CPP. CPP; central precocious puberty; GnRHa, gonadotropin-releasing hormone analog.

\section{Correlations between Variables Influencing FH}

In patients with CPP due to MKRN3 mutation, there were positive and significant correlations between $\mathrm{FH}$ and height SDS at the diagnosis and the end of GnRHa treatment $(r=0.8, p=0.005$, and $r=0.76, p=0.0063$ respectively).

Regarding FH of the 43 girls with idiopathic CPP, there were a positive and significant correlations between FH SDS and height SDS at the diagnosis and the end of GnRHa treatment $(r=0.734, p<0.0001$ and $r=0.79, p<$ 0.001 , respectively), as well as between FH and post-treat- ment growth after GnRHa $(r=0.5, p=0.0006)$, and FH and TH $(r=0.44, p=0.004)$.

\section{Metabolic and Reproductive Outcomes}

The long-term follow-up of the metabolic and reproductive parameters was done for a subset of patients with CPP: 7 patients with CPP due to MKRN3 mutations and 35 patients with idiopathic CPP. In patients with CPP due to MKRN3 mutations, insulin resistance was identified in 1 patient and high LDL levels were identified in 2 patients with high BMI, indicating that 3 out of 7 patients had 
metabolic abnormalities; hypertriglyceridemia was not identified in these patients. In the 35 patients with idiopathic CPP, insulin resistance was identified in 4 patients (11.4\%), high LDL levels in 3 patients (8.6\%), and hypertriglyceridemia in 1 patient $(2.8 \%$; Table 2$)$. Therefore, metabolic abnormalities were present in $17.1 \%$ of patients with idiopathic CPP. These metabolic abnormalities occurred in patients with normal and high BMI. Diabetes and hypertension were not observed in this cohort (Table 2).

In patients with CPP due to MKRN3 mutation and those with idiopathic CPP, the mean interval between the discontinuation of $\mathrm{GnRHa}$ treatment and the occurrence of spontaneous menarche was $0.9 \pm 0.7$ and $1.1 \pm 0.5$ years, respectively, $p=0.27$. In addition, the mean CA of menarche was $11.5 \pm 1.3$ and $12 \pm 0.6$ years for patients with CPP due to MKRN3 mutations and those with idiopathic CPP, respectively, $p=0.1$. Abnormal menstrual cycles were reported by 2 out of $11(18.2 \%)$ patients with CPP due to MKRN3 mutation and by $6 / 33$ (18.1\%) patients with idiopathic CPP. Clinical and/or laboratory criteria for hyperandrogenism were positive for 4 patients with CPP due to MKRN3 mutations and for 34 patients with idiopathic CPP (Table 2). One patient with CPP due to MKRN3 mutation and 4 patients with idiopathic CPP had hyperandrogenism. One patient with CPP due to $M K R N 3$ mutation and 6 patients with idiopathic CPP fulfilled criteria for polycystic ovarian (ovarian volume $>10$ $\mathrm{mL}$ ) in pelvic ultrasound. One patient with CPP due to $M K R N 3$ mutation and 2 with idiopathic CPP group were positive for PCOS criteria, which was in accordance with the Rotterdam PCOS criteria [29]. Basal progesterone levels were at an ovulatory range in 2 and 6 patients with CPP due to MKRN3 mutations and idiopathic CPP respectively. One patient became pregnant and conceived a healthy offspring. Clinical and laboratory data at adulthood are summarized in Table 2.

\section{Discussion}

Long-acting GnRHas are the treatment of choice for CPP, and outcomes after treatment of idiopathic CPP have been described in several studies $[3,10,30]$. In contrast, long-term follow-up of patients with CPP due to loss-of-function mutations of MKRN3 after GnRHa withdrawal has not been reported so far $[6,31,32]$. In the present study, we have described the initial clinical and hormonal data of 29 female patients with CPP due to MKRN3 mutations and long-term follow-up of a subset group (11

Outcomes of Patients with CPP with or without MKRN3 Mutations patients), taking into consideration anthropometric, metabolic, and reproductive features.

In this study, the mean CA of pubertal onset was similar in patients with CPP due to MKRN3 mutations and in those with idiopathic $\mathrm{CPP}$, confirming the data reported previously $[31,32]$. In contrast with our data, Simon et al. [6] demonstrated that girls with CPP due to MKRN3 mutation were younger at puberty onset than those without MKRN3 mutation [6].

A systematic review and meta-analysis on MKRN3 mutations concerning CPP, which was reported earlier, included 22 studies comprising 880 patients with CPP [32]; 89 (76 girls) of them had MKRN3 defects [32]; in the pooled comparative analysis of clinical and biochemical data between girls and boys, the authors reported significant differences in clinical (age at pubertal onset and at diagnosis) and hormonal (basal FSH) parameters, which is related to sex-dimorphic characteristics. Conversely, we compared data between female patients with and without MKRN3 mutations, and no clinical or laboratory parameter was indicative of harboring MKRN3 defects. Regarding hormonal data, Macedo et al. [31] previously reported a higher level of mean basal FSH in girls with MKRN3 mutations compared to those without MKRN3 mutations.

Regarding family history, the meta-analysis showed a prevalence of $M K R N 3$ mutation of $19 \%$ in patients with familial CPP and $2 \%$ in patients with sporadic CPP [28]. In our cohort, the familial history of precocious puberty was positive in all patients with CPP due to MKRN3 mutations and in $25.6 \%$ of patients with idiopathic CPP, suggesting that other genetic defects can be probably involved in the etiology of CPP. It must be noted that the high prevalence of familial history in patients with MKRN3 mutations in our cohort must be interpreted cautiously, because familial history was an inclusion criterion to perform genetic analysis in some cases.

Whether or not the severity of MKRN3 mutation has any influence on the clinical and hormonal phenotype of CPP remains unknown. Valadares et al. [32] showed that the age during diagnosis of CPP was significantly low in patients with severe MKRN3 mutations. The impact of the subtype of MKRN3 mutations on long-term followup of these patients was not evaluated in the present study because most of the patients (10/11) had severe mutations.

Patients with CPP caused by MKRN3 mutations or idiopathic form were treated with a monthly or 3-month low dosage of leuprorelin acetate, 3.75 or $11.25 \mathrm{mg}$, respectively, and the efficacy of GnRHa did not differ be- 
tween these groups, resulting in satisfactory anthropometric outcomes. The $\mathrm{FH}$ within $\mathrm{TH}$ range was reached in all except 1 patient with CPP due to MKRN3 mutations and in all but 1 patient with idiopathic CPP. In patients with CPP due to MKRN3 mutations, we were not able to rule out that the father harboring MKRN3 mutation had not been affected by CPP, which could negatively influence the TH. No statistically significant difference was found between mean $\mathrm{FH}$ and mean $\mathrm{TH}$ in treated patients having CPP due to MKRN3 mutations and treated patients with idiopathic CPP. The present study is the first report on the $\mathrm{FH}$ of patients with $\mathrm{CPP}$ due to $M K R N 3$ mutations treated with GnRHa, indicating that MKRN3 defect did not influence FH.

With regard to the BMI and body composition, the prevalence of overweightness and obesity during diagnosis of CPP was equally elevated in patients with and without MKRN3 mutations, which is in accordance with several studies that reported high BMI during diagnosis of CPP $[11,12]$. At the end of GnRHa treatment, the prevalence of overweight and obesity decreased in both groups. The effect of GnRHa treatment on BMI and body composition was explored in several studies, indicating that during GnRHa treatment, no significant mean or individual BMI-SDS change occurs [11, 12, 33, 34]. However, an increase in the percentage of total fat mass has been demonstrated during GnRHa treatment [16]. At the FH, it is noteworthy that a significant reduction in the prevalence of overweight or obesity was observed in both CPP groups. Other studies have also reported a reduction in $\mathrm{BMI}$ in patients with idiopathic CPP $[17,35]$. These data suggest that changes in $\mathrm{BMI}$ and body composition were not influenced by MKRN3 mutations. The longitudinal analysis of categorical BMI in both groups revealed similar evolution. This information was lacking in previous studies on MKRN3 mutations [32].

In a large cohort of treated and untreated women with idiopathic CPP, Lazar et al. [14] demonstrated that the prevalence of obesity-related complications, such as metabolic dysfunctions and cancer comorbidities, was not increased, regardless of GnRHa treatment. In this cohort, the prevalence of metabolic dysfunctions at adulthood was not significantly different between patients with CPP due to $M K R N 3$ mutations and those with idiopathic CPP. These data can indicate that $M K R N 3$ has no direct role in metabolic regulation.

As already described, for women with idiopathic CPP and were treated, the gonadal function is restored at the predicted time after cessation of GnRHa treatment, with subsequent menarche and regular ovulatory menstrual cycles $[11,15]$. In our study, female patients with CPP due to MKRN3 mutations and treated with GnRHa also had normal recovery of the gonadotropic axis after discontinuation of GnRHa treatment. Furthermore, spontaneous menarche occurred at the same CA in patients with CPP due to MKRN3 mutations and idiopathic form. The prevalence of PCOS was equally low in both groups.

In conclusion, we reported the initial presentation and the longest follow-up of patients with CPP due to MKRN3 mutations, treated with $\mathrm{GnRHa}$, including anthropometric, hormonal, metabolic, and reproductive profiles. All patients reached normal $\mathrm{FH}$, demonstrating the efficacy of $\mathrm{GnRHa}$ in preserving genetic adult height potential, regardless of the etiology of CPP. The prevalence of metabolic and reproductive disorders was similar in patients with CPP due to MKRN3 mutations and idiopathic CPP, indicating that $M K R N 3$ mutations are not associated with a distinct short- and long-term follow-up compared with idiopathic CPP.

\section{Acknowledgment}

We appreciate the cooperation of the national (Ribeirao Preto Medical School, University of Sao Paulo, Universidade Estadual de Campinas, Faculdade de Ciências Médicas, private office Governador Valadares-MG, Universidade do Estado do Rio de JaneiroRJ) and international Services (Division of Endocrinology, Diabetes, and Metabolism, Nemours Children's Clinic, Jacksonville, FL, USA; Department of Pediatrics, University Hospital Gasthuisberg, University of Leuven, Leuven, Belgium; Hospital de Niños R. Gutiérrez, Buenos Aires, Argentina; Department of Pediatric Endocrinology, University of Health Sciences, Umraniye Training and Research Hospital, Adem Yavuz Caddesi, Elmalıkent Mah. Yekta Sok, Istanbul, Turkey; Pediatric Endocrine and Diabetes Unit the Chaim Sheba Medical Center, Israel).

\section{Statement of Ethics}

The protocol was approved by all the local Ethics Committee. Written informed consent was obtained from all participants and/ or their guardians.

\section{Disclosure Statement}

The authors have no conflicts of interest to disclose. 


\section{References}

1 Parent AS, Teilmann G, Juul A, Skakkebaek NE, Toppari J, Bourguignon JP. The timing of normal puberty and the age limits of sexual precocity: variations around the world, secular trends, and changes after migration. Endocr Rev. 2003 Oct;24(5):668-93.

2 Carel JC, Léger J. Clinical practice. Precocious puberty. N Engl J Med. 2008 May;358(22): 2366-77.

3 Latronico AC, Brito VN, Carel JC, Paulo DS, Robert H. Causes, diagnosis, and treatment of central precocious puberty. Lancet Diabetes Endocrinol. 2016 Mar;4(3):265-74.

4 Abreu AP, Dauber A, Macedo DB, Noel SD, Brito VN, Gill JC, et al. Central precocious puberty caused by mutations in the imprinted gene MKRN3. N Engl J Med. 2013 Jun; 368(26):2467-75.

5 Bulcao Macedo D, Nahime Brito V, Latronico AC. New causes of central precocious puberty: the role of genetic factors. Neuroendocrinology. 2014;100(1):1-8.

6 Simon D, Ba I, Mekhail N, Ecosse E, Paulsen A, Zenaty D, et al. Mutations in the maternally imprinted gene MKRN3 are common in familial central precocious puberty. Eur J Endocrinol. 2016 Jan;174(1):1-8.

7 Bessa DS, Macedo DB, Brito VN, França MM, Montenegro LR, Cunha-Silva M, et al. High Frequency of MKRN3 Mutations in Male Central Precocious Puberty Previously Classified as Idiopathic. Neuroendocrinology. 2017;105(1):17-25.

8 Macedo DB, França MM, Montenegro LR, Cunha-Silva M, Best DS, Abreu AP, et al. Central Precocious Puberty Caused by a Heterozygous Deletion in the MKRN3 Promoter Region. Neuroendocrinology. 2018;107(2): 127-32.

9 Mansfield MJ, Beardsworth DE, Loughlin JS, Crawford JD, Bode HH, Rivier J, et al. Longterm treatment of central precocious puberty with a long-acting analogue of luteinizing hormone-releasing hormone. Effects on somatic growth and skeletal maturation. N Engl J Med. 1983 Nov;309(21):1286-90.

10 Carel JC, Eugster EA, Rogol A, Ghizzoni L, Palmert MR, Antoniazzi F, et al.; ESPE-LWPES GnRH Analogs Consensus Conference Group. Consensus statement on the use of gonadotropin-releasing hormone analogs in children. $\mathrm{Pe}$ diatrics. 2009 Apr;123(4):e752-62.

11 Pasquino AM, Pucarelli I, Accardo F, Demiraj V, Segni M, Di Nardo R. Long-term observation of 87 girls with idiopathic central precocious puberty treated with gonadotropinreleasing hormone analogs: impact on adult height, body mass index, bone mineral content, and reproductive function. J Clin Endocrinol Metab. 2008 Jan;93(1):190-5.

12 Brito VN, Latronico AC, Cukier P, Teles MG, Silveira LF, Arnhold IJ, et al. Factors determining normal adult height in girls with gonadotropin-dependent precocious puberty treated with depot gonadotropin-releasing hormone analogs. J Clin Endocrinol Metab. 2008 Jul;93(7):2662-9.

13 Klein KO, Barnes KM, Jones JV, Feuillan PP, Cutler GB Jr. Increased final height in precocious puberty after long-term treatment with LHRH agonists: the National Institutes of Health experience. J Clin Endocrinol Metab. 2001 Oct;86(10):4711-6.

14 Lazar L, Lebenthal Y, Yackobovitch-Gavan M, Shalitin S, de Vries L, Phillip M, et al. Treated and untreated women with idiopathic precocious puberty: BMI evolution, metabolic outcome, and general health between third and fifth decades. J Clin Endocrinol Metab. 2015 Apr;100(4):1445-51.

15 Lazar L, Meyerovitch J, de Vries L, Phillip M, Lebenthal Y. Treated and untreated women with idiopathic precocious puberty: longterm follow-up and reproductive outcome between the third and fifth decades. Clin Endocrinol (Oxf). 2014 Apr;80(4):570-6.

16 Chiocca E, Dati E, Baroncelli GI, Mora S, Parrini $\mathrm{D}$, Erba $\mathrm{P}$, et al. Body mass index and body composition in adolescents treated with gonadotropin-releasing hormone analogue triptorelin depot for central precocious $\mathrm{pu}$ berty: data at near final height. Neuroendocrinology. 2009;89(4):441-7.

17 Guaraldi F, Beccuti G, Gori D, Ghizzoni L. MANAGEMENT OF ENDOCRINE DISEASE: long-term outcomes of the treatment of central precocious puberty. Eur J Endocrinol. 2016 Mar;174(3):R79-87.

18 Lee PA. Laboratory monitoring of children with precocious puberty. Arch Pediatr Adolesc Med. 1994 Apr;148(4):369-76.

19 Brito VN, Batista MC, Borges MF, Latronico AC, Kohek MB, Thirone AC, et al. Diagnostic value of fluorometric assays in the evaluation of precocious puberty. J Clin Endocrinol Metab. 1999 Oct;84(10):3539-44.

20 Greulich W, Pyle S. Radiographic Atlas of Skeletal Development of the Hand and Wrist. Stanford (CA): Stanford University Press; 1959.

21 Debeneix C, Bourgeois M, Trivin C, SainteRose C, Brauner R. Hypothalamic hamartoma: comparison of clinical presentation and magnetic resonance images. Horm Res. 2001; 56(1-2):12-8

22 Macedo DB, Cukier P, Mendonca BB, Latronico AC, Brito VN. Avanços na etiologia, no diagnóstico e no tratamento da puberdade precoce central. Arq Bras Endocrinol Metabol. 2014 Mar;58(2):108-17.

23 Marshall WA, Tanner JM. Variations in pattern of pubertal changes in girls. Arch Dis Child. 1969 Jun;44(235):291-303.

24 Marshall WA, Tanner JM. Variations in the pattern of pubertal changes in boys. Arch Dis Child. 1970 Feb;45(239):13-23.

25 Styne DM, Arslanian SA, Connor EL, Farooqi IS, Murad MH, Silverstein JH, et al. Pediatric
Obesity-Assessment, Treatment, and Prevention: An Endocrine Society Clinical Practice Guideline. J Clin Endocrinol Metab. 2017 Mar;102(3):709-57.

26 Borecki IB, Higgins M, Schreiner PJ, Arnett DK, Mayer-Davis E, Hunt SC, et al. Evidence for multiple determinants of the body mass index: the National Heart, Lung, and Blood Institute Family Heart Study. Obes Res. 1998 Mar;6(2):107-14.

27 Qu HQ, Li Q, Rentfro AR, Fisher-Hoch SP, McCormick JB. The definition of insulin resistance using HOMA-IR for Americans of Mexican descent using machine learning. PLoS One. 2011;6(6):e21041.

28 Legro RS, Arslanian SA, Ehrmann DA, Hoeger KM, Murad MH, Pasquali R, et al.; Endocrine Society. Diagnosis and treatment of polycystic ovary syndrome: an Endocrine Society clinical practice guideline. J Clin Endocrinol Metab. 2013 Dec;98(12):4565-92.

29 Rotterdam ESHRE/ASRM-Sponsored PCOS Consensus Workshop Group. Revised 2003 consensus on diagnostic criteria and longterm health risks related to polycystic ovary syndrome. Fertil Steril. 2004 Jan;81(1):1925.

30 Bangalore Krishna K, Fuqua JS, Rogol AD, Klein KO, Popovic J, Houk CP, et al. Use of Gonadotropin-Releasing Hormone Analogs in Children: Update by an International Consortium. Horm Res Paediatr. 2019;91(6):35772.

31 Macedo DB, Abreu AP, Reis AC, Montenegro LR, Dauber A, Beneduzzi D, et al. Central precocious puberty that appears to be sporadic caused by paternally inherited mutations in the imprinted gene makorin ring finger 3. J Clin Endocrinol Metab. 2014 Jun;99(6): E1097-103.

32 Valadares LP, Meireles CG, De Toledo IP, Santarem de Oliveira R, Gonçalves de Castro LC, Abreu AP, et al. MKRN3 Mutations in Central Precocious Puberty: A Systematic Review and Meta-Analysis. J Endocr Soc. 2019 Mar;3(5):979-95.

33 Lazar L, Padoa A, Phillip M. Growth pattern and final height after cessation of gonadotropin-suppressive therapy in girls with central sexual precocity. J Clin Endocrinol Metab. 2007 Sep;92(9):3483-9.

34 Heger S, Partsch CJ, Sippell WG. Long-term outcome after depot gonadotropin-releasing hormone agonist treatment of central precocious puberty: final height, body proportions, body composition, bone mineral density, and reproductive function. J Clin Endocrinol Metab. 1999 Dec;84(12):4583-90.

35 Arrigo T, De Luca F, Antoniazzi F, Galluzzi F, Segni M, Rosano M, et al. Reduction of baseline body mass index under gonadotropinsuppressive therapy in girls with idiopathic precocious puberty. Eur J Endocrinol. 2004 Apr;150(4):533-7. 